\title{
Microstructural influences on strengthening in a naturally aged and overaged Al-Cu-Li-Mg based alloy
}

\author{
Henry Ovri $^{*}$, Eric A. Jägle ${ }^{2}$, Andreas Stark ${ }^{3}$, Erica T. Lilleodden ${ }^{1}$ \\ ${ }^{1}$ Helmholtz Zentrum Geesthacht, Institute of Materials Research, Materials Mechanics, 21502 \\ Geesthacht, Germany. \\ ${ }^{2}$ Max-Planck-Institut für Eisenforschung GmbH, Department of Microstructure Physics and Alloy \\ Design, 40237 Düsseldorf, Germany \\ ${ }^{3}$ Helmholtz Zentrum Geesthacht, Institute of Materials Research, Materials Physics, 21502 \\ Geesthacht, Germany. \\ *Corresponding author's contact information: \\ Email: henry.ovri@hzg.de \\ Telephone: +49-4152-872607 \\ Fax: +49-4152-872625
}

\begin{abstract}
A combination of transmission electron microscopy, atom probe tomography and highenergy X-ray diffraction was employed to investigate the influence of local microstructural changes on strengthening in a commercial Al-Li-Cu based alloy, AA2198, in the stretched and naturally aged, and overaged states. Strengthening in the stretched and naturally aged temper was shown to be governed by a combination of $\mathrm{Cu}-\mathrm{Cu}$ clusters, $\delta^{\prime} / \beta^{\prime}$ phase and solution strengthening. This is in contrast to another report which suggest that strength in this temper is only due to Cu-rich clusters [Decreus B et. al. Acta Mater 61 (2013) 2207]. On the other hand, although large volume fractions of equilibrium phases such as $\mathrm{T}_{\mathrm{B}}$, and $\theta$ were present in the overaged temper, its strengthening was largely governed by order hardening, which is the strengthening mechanism associated with the $\delta^{\prime} / \beta^{\prime}$ phase. The $\delta^{\prime} / \beta^{\prime}$ phase remained in the matrix even after extensive overaging.
\end{abstract}

Keywords: TEM, APT, Al-Li-Cu alloys, precipitates, strengthening mechanisms. 


\section{Introduction}

Al-Cu-Li-Mg based alloys of the latest generation exhibit an excellent combination of low density, high elastic modulus and high specific strength, which makes them candidate structural materials for next generation aerospace applications [1]-[4]. The attractive properties of these alloys are associated with the addition of Li which not only results in significant weight reduction but also enables the formation of several strengthening precipitates including $\delta^{\prime}\left(\mathrm{Al}_{3} \mathrm{Li}\right), \delta(\mathrm{AlLi}), \mathrm{T}_{1}\left(\mathrm{Al}_{2} \mathrm{CuLi}\right), \mathrm{T}_{2}\left(\mathrm{Al}_{5} \mathrm{CuLi}_{3}\right)$ and $\mathrm{T}_{\mathrm{B}}\left(\mathrm{Al}_{7} \mathrm{Cu} \mathrm{Cu}_{4} \mathrm{Li}\right)$. Other precipitates that have been reported in these alloys include GP zones, $\theta^{\prime}\left(\mathrm{Al}_{2} \mathrm{Cu}\right), \theta$ $\left(\mathrm{Al}_{2} \mathrm{Cu}\right), \quad \Omega \quad\left(\mathrm{Al}_{2} \mathrm{Cu}\right), \quad \mathrm{S}^{\prime} \quad\left(\mathrm{Al}_{2} \mathrm{CuMg}\right), \quad \beta^{\prime} \quad\left(\mathrm{Al}_{3} \mathrm{Zr}\right) \quad$ [3]-[8]. The concentration and thermomechanical treatment given to a particular alloy dictates which of these precipitates forms in the alloy and ultimately determines its properties.

Recent studies of Al-Cu-Li-Mg-based alloy systems have focussed on AA2198 [9][12], which has shown an outstanding combination of static strength and damage tolerance along with good weldability and is therefore envisaged as a replacement for the AA2024/AA7475 alloys presently used in fuselage skin applications in commercial aircrafts [13][14]. Although the peak aged (PA) temper of this alloy is of application interest, detailed investigation of the structure-property relationships of other temper states is required since it provides the basis for understanding the influence of process-induced microstructural changes on the postprocessing properties of the alloy. For instance, it was shown that the $\mathrm{T}_{1}$ precipitate, which is the main strengthening phase in the PA temper [1][12], dissolves, while $\mathrm{T}_{B}$ phase precipitates within the grain interior and in grain boundaries during friction stir welding of peak aged AA2198 [15]. The $T_{B}$ phase is an equilibrium phase that occurs only in the overaged temper of Al-Li based alloy systems [8]. It was shown elsewhere [16] that Portevin-Le-Chatelier (PLC) type plastic instability, a phenomenon associated with strain localization and reduction in ductility [17], occurs in the overaged (OA) temper of this alloy. This phenomenon refers to 
continuous yielding that occurs during plastic deformation, i.e. prior to necking and it manifests macroscopically as serrations (stress drops) in the plastic region of stress-strain curves. This is in addition to the significant reduction in strength that accompanies overaging. Similarly, it was recently concluded that the stretched and naturally aged (NA) temper of AA2198 must be strengthened by $\mathrm{Cu}$-rich clusters, since no precipitates were observed in selected area diffraction (SAD) or dark field (DF) transmission electron microscope (TEM) micrographs [1]. It is not clear from these studies if these clusters are associated with $\mathrm{Mg}$ or Li. $\mathrm{Cu}-\mathrm{Mg}$ co-clusters form easily during room temperature ageing of a number of $\mathrm{Al}-\mathrm{Cu}-$ Mg-(Li) alloy systems and are known to confer significant strengthening [18]-[19]. $1^{\text {st }}$ nearest neighbour distribution $(1 \mathrm{NN})$ analysis of atom probe tomography data of this temper state revealed only a slight deviation from the random distribution of $\mathrm{Cu}$ in the matrix [20]. Whether such minor deviations can sufficiently account for the remarkably high strength observed in this temper is an open question.

In this paper, we present a detailed study of the microstructure-property relationship of an AA2198 alloy in the stretched and naturally aged (NA) and overaged (OA) states where the $\mathrm{T}_{1}$ phase is absent. A systematic approach involving TEM methods, high-energy X-ray diffraction (HEXRD) and APT was adopted.

\section{Materials and methods}

The nominal composition of the AA2198 alloy used in the present study is given in Table 1. The alloy was received in the T351 state, that is, it had been solution treated, water quenched, stretched to a strain of $2 \%$ and naturally aged for several months. The as-received temper is hereafter referred to as NA. An artificial aging protocol aimed at achieving the overaged state $(\mathrm{OA})$ within a reasonable ageing time was established on the basis of the timetemperature-precipitation diagrams proposed by Chen and Bhat [21] for a similar alloy, AA2195. The protocol comprised aging at $370^{\circ} \mathrm{C}$ for 10 hours. 
The mechanical response of the investigated tempers was determined from tensile tests conducted at a strain rate of $5 \times 10^{-5} / \mathrm{s}$ in a Zwick universal testing station equipped with a noncontact extensometer. Dog-bone shaped samples with gauge length of $11 \mathrm{~mm}$ and thickness of $0.6 \mathrm{~mm}$, produced by wire-cut electro-discharge machining, were used in the tensile tests.

Microstructural characterization was conducted in large part through TEM analysis using a Philips CM200 TEM and a JEOL 3010 microscope operated at 200KV and 300KV, respectively. A set of the TEM samples used in the analysis was prepared by electropolishing in a twin-jet device with a solution of $67 \%$ methanol and $33 \%$ nitric acid at a temperature of $20^{\circ} \mathrm{C}$ and current of $12 \mathrm{~V}$, while another set was produced by focused ion beam (FIB) milling in a Nova 200 Nanolab dual-beam scanning electron microscope (SEM) from FEI, Co. The thickness of the FIB-milled lamellae was measured in the SEM prior to examination in the TEM and used as the basis for determining the average volume fraction of the $\delta^{\prime} / \beta$ 'phase. The reported volume fraction of the $\delta^{\prime} / \beta^{\prime}$ phase is the average estimated from three different micrographs, while its precipitate size is the average of over 180 precipitates imaged in a series of micrographs.

Complementary microstructural characterization using high-energy x-ray diffraction (HEXRD) was carried out at the HZG beamline HEMS at the Deutsches ElectronenSynchrotron (DESY) in Hamburg, Germany [22]. Samples with height of $4 \mathrm{~mm}$ were measured in transmission using a beam cross section of $1 \mathrm{~mm} \times 1 \mathrm{~mm}$. The samples were penetrated with high-energy X-rays with a photon energy of $100 \mathrm{KeV}$, which corresponds to a wavelength, $\lambda$, of $0.124 \AA$. The resulting Debye-Scherrer diffraction rings were recorded on a 2-dimensional Perkin Elmer XRD 1622 detector with an exposure time of 0.1seconds. In order to reduce background noise, 40 images were summed up for each sample, such that even weak peaks from phases with minor phase fractions were made visible. Conventional diffraction patterns were generated from the rings by azimuthal integration of the rings. 
Qualitative phase analysis was achieved by means of simulated diffraction patterns. The lattice parameter of the aluminium phase was determined by the Gaussian fitting method.

Quantitative elemental analysis of the matrix phase and clustering therein was carried out with a LEAP 3000X HR, local electrode atom probe operating in laser mode. The specimen temperature was set to $60 \mathrm{~K}$, the laser pulse energy was $0.6 \mathrm{~nJ}$, the laser pulse repetition rate varied between 100 and $250 \mathrm{kHz}$, and the target evaporation rate was set to $1 \%$ [23]. The specimens were produced by a standard lift-out procedure [24] in the Nova 200 Nanolab dual beam SEM mentioned above. The final annular milling was carried out at an accelerating voltage of $5 \mathrm{kV}$ and a beam current of $70 \mathrm{pA}$. Nevertheless, some Ga contamination was detected in the APT datasets, but the corresponding peaks in the mass spectrum were ignored in the concentration and cluster analysis. There were also unusually intense peaks corresponding to $\mathrm{AlH}^{+}$and $\mathrm{AlH}_{2}{ }^{+}$in the mass spectrum. This impedes the correct determination of the Si concentration, because both $\mathrm{AlH}^{+}$and ${ }^{28} \mathrm{Si}^{+}$, and $\mathrm{AlH}_{2}{ }^{+}$and ${ }^{29} \mathrm{Si}^{+}$have mass-to-charge ratios of 28 and 29, respectively. In this study, the peak at $28 \mathrm{Da}$ was assigned to $\mathrm{Si}$ while that at $29 \mathrm{Da}$ was assigned to $\mathrm{AlH}_{2}$. 3D reconstruction was performed in the software IVAS (version 3.6.8) by Cameca using the initial tip apex radii and shank angles as determined by SEM before the experiments. Cluster analysis was performed in the software 3Depict (version 0.0.17) using the core-link algorithm. The cluster analysis parameters were determined according to the heuristic method used by Marceau [25].

\section{Results}

\subsection{Tensile test}

Figure 1 shows the true stress, $\sigma_{t}$, vs. true strain, $\varepsilon_{t}$, response of each temper. The NA temper exhibited remarkably high yield strength, $310 \mathrm{MPa}$, about a factor of three higher than in the OA temper. PLC type - plastic instability was also observed in the OA temper. A portion of the $\sigma_{\mathrm{t}}$, vs. $\varepsilon_{\mathrm{t}}$ curve of the OA temper is magnified in the insert in Figure 1 to more 
clearly reveal the stress drops associated with the plastic instability. It is noteworthy that the NA temper sustained a higher plastic strain than the OA temper even though its yield strength is about a factor of 3 higher than the latter. This observation underscores the detrimental effect of plastic instability on ductility. A plot of the work hardening rate $\left(d \sigma_{t} / d \varepsilon_{t}\right)$ as a function of true strain is also superimposed on Figure 1. The very early stage of plastic deformation in the OA tempers showed significantly higher work hardening rate in comparison to the NA temper. The high work hardening rate of the OA temper however decreased rapidly, after only about $2 \%$ plastic strain, to values lower than those obtained in the other tempers. This kind of response, namely the exceptionally high initial work hardening rate at the onset of plasticity followed quickly by a significant decrease, is typical of alloys containing a dispersion of incoherent, non-shearable second phase precipitates and is attributed to the back-stress exerted by the Orowan loops formed around the precipitates on subsequent mobile dislocations [26]. This mechanism is known to breakdown after about $2 \%$ plastic strain as a result of the plastic relaxation in the interface between the matrix and the precipitates. It is reported that geometrically necessary dislocations which are stored to accommodate the strain gradient between the deforming matrix and the non-deforming particle, drive the plastic relaxation [26]. On the other hand, the initial work hardening rates such as those found in the NA temper, have been attributed to increased strength of the dislocation junctions owing to high solute contents [10]. 


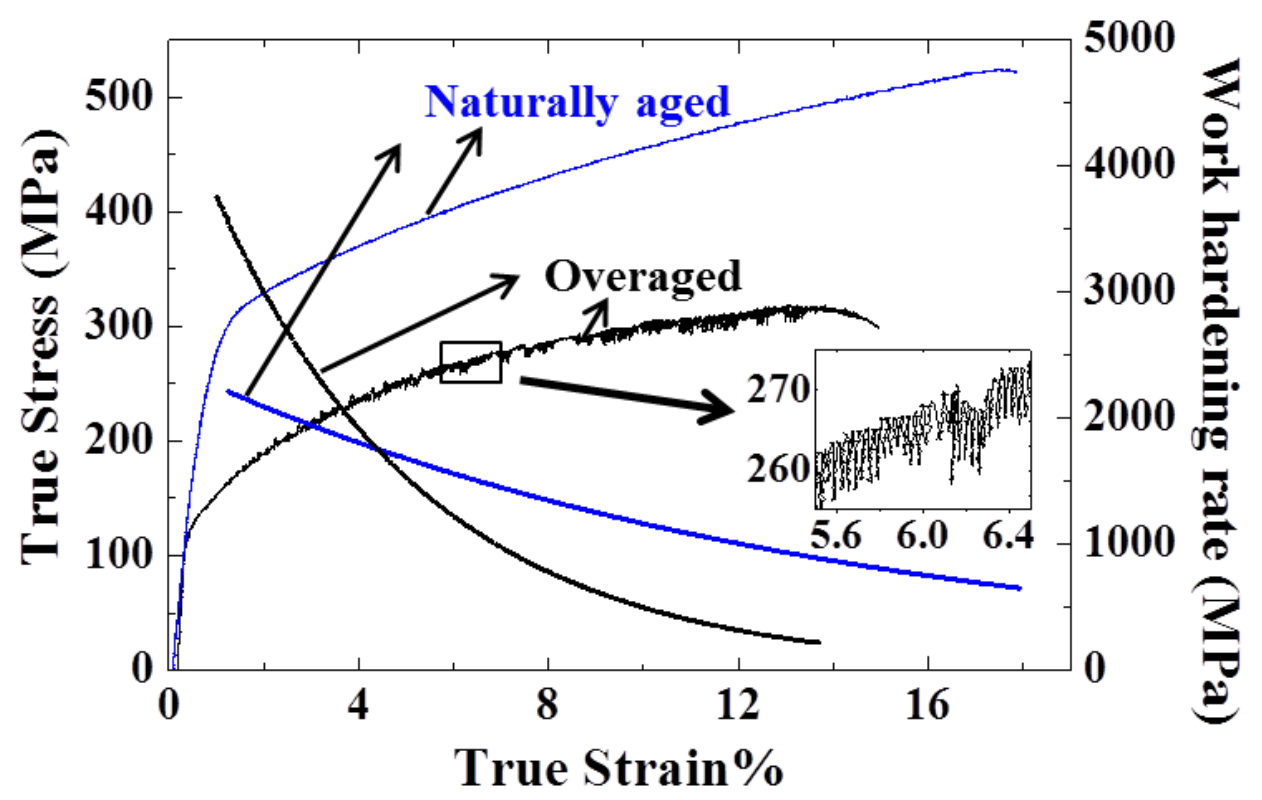

Figure 1(a): True stress-true strain response of AA2198 in the naturally aged (NA), in blue, and overaged (OA), in black, temper states. Plastic instabilities are observed in the overaged temper. (b) Work hardening rates $\left(\mathrm{d} \sigma_{t} / d \varepsilon_{t}\right)$ of each temper plotted as a function of true plastic strain.

\subsection{TEM analysis}

A bright field (BF) and dark field (DF) image of the NA temper is shown in Figure 2(a) \& (b), respectively. The DF image was made from a superlattice spot characteristic of $\delta^{\prime} / \beta^{\prime}$ phase in an orientation slightly tilted away from a $\langle 100\rangle_{\mathrm{Al}}$ zone axis selected area diffraction (SAD) pattern. The average radius and volume fraction of the $\delta^{\prime} / \beta^{\prime}$ phase in this temper are $10 \pm 5 \mathrm{~nm}$ and $0.004 \pm 6 \mathrm{e}-4$ respectively. In contrast to this observation, Decreus [1] did not observe any precipitate in the stretched and naturally aged temper of the AA2198 alloy they investigated. In the present work, precipitates were also observed in some of the grain boundaries of the NA temper. These are likely equilibrium precipitates or disperoids that were undissolved during the solution treatment. The absence of reflections arising from such precipitates however suggests that their volume fraction is very low. A two-beam dark field image showing the typical dislocation structure found in the NA temper is shown in Figure 2(c). The dislocations are typically wavy, unevenly arranged, tangled and appear pinned by 
precipitates at several points along their line length. No evidence of dislocation pairs could be found.

In the case of the OA temper, the key microstructural features observed within the grain interior can be seen in the BF image shown in Figure 2(d). A large spherical precipitate with radius in excess of $200 \mathrm{~nm}$ identified as the $\mathrm{T}_{2}$ phase is highlighted in the micrograph. SAD patterns taken only from this precipitate (not shown) revealed the icosahedral symmetry that is associated with the $\mathrm{T}_{2}$ phase. However, the $\mathrm{T}_{2}$ phase was mostly found along the grain boundaries. Large $\mathrm{T}_{\mathrm{B}}$ precipitates were also observed within the grain interior and along the grain boundaries. Faint superlattice reflections indicative of the presence of the $\delta^{\prime} / \beta^{\prime}$ phase are still evident in the $\langle 112\rangle_{\mathrm{Al}}$ zone axis SAD pattern inserted in Figure 2(e). Reflections associated with the $T_{B}$ phase can also be seen in the SAD pattern. A DF image made from one of the superlattice spots is shown in Figure 2(e). The average radius and average volume fraction of the $\delta^{\prime} / \beta^{\prime}$ precipitates in this phase are $11 \pm 6 \mathrm{~nm}$ and $0.006 \pm 0.002$, respectively; these values are only slightly higher than those found in the NA temper. The absence of streaks and reflections associated with the $\mathrm{T}_{1}, \theta^{\prime}$ and $\Omega$ phases in the $\langle 112\rangle_{\mathrm{Al}} \mathrm{SAD}$ pattern inserted in Figure 2(e) indicate that these phases, which are likely to have formed during the early stages of aging at $370^{\circ} \mathrm{C}$ have dissolved, facilitating the precipitation of more equilibrium phases such as $\mathrm{T}_{\mathrm{B}}$ phase. Time-Temperature-Transformation (TTT) diagrams proposed for a similar alloy AA2195 [21] strongly suggest that the $\mathrm{T}_{1}$ and $\theta^{\prime}$ phases precipitate in less than 60 s at temperatures around $204^{\circ} \mathrm{C}$ and $370{ }^{\circ} \mathrm{C}$, respectively. Figure 2(f) shows the typical dislocation configuration found in the OA temper. The dislocations are mostly arranged in planar arrays and are uniformly distributed on individual planes. This is an indication that slip is mostly planar in this temper. It is also evident from the micrograph that the dislocations are pinned at several points around their line lengths by the $\delta^{\prime} / \beta^{\prime}$ 
precipitates as well as by the large precipitates. Coherent $\delta^{\prime} / \beta^{\prime}$ precipitates, as indicated by lines of no contrast perpendicular to the g-vector, are also observed in Figure 2(f).

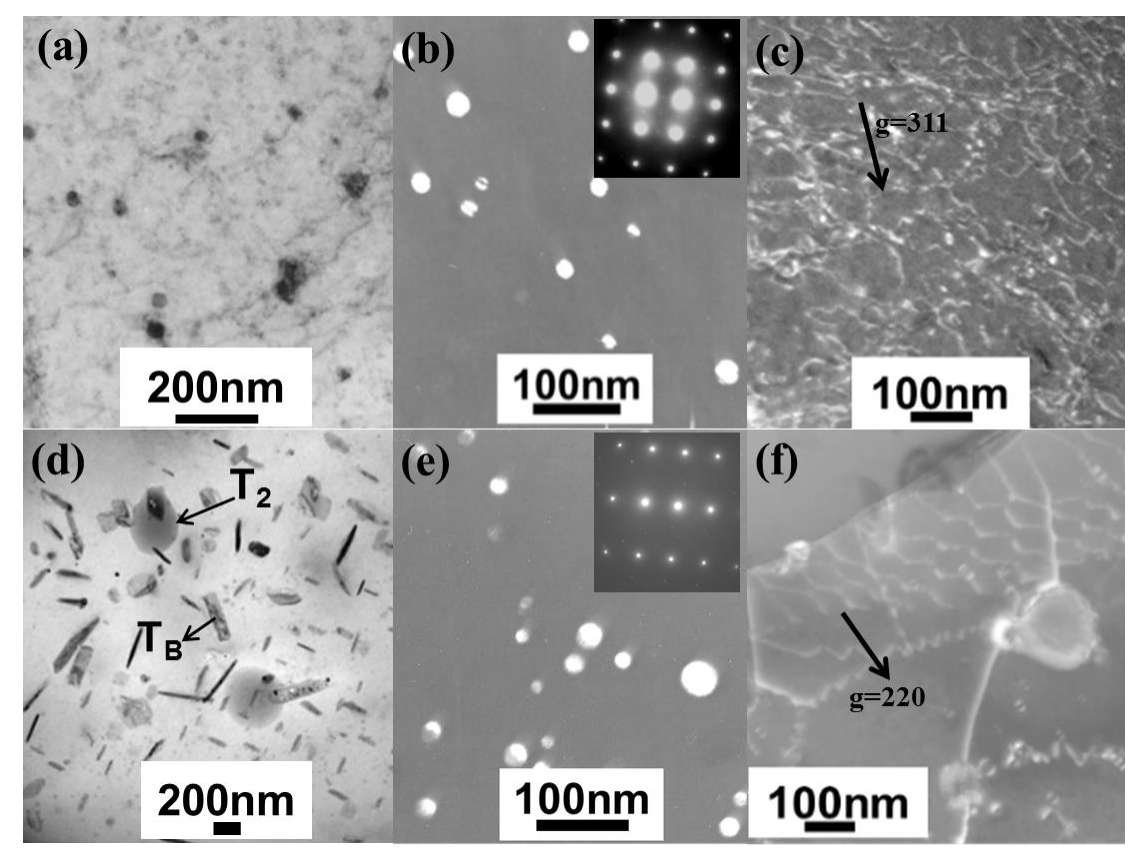

Figure 2: (a) Bright field and (b) dark field images of the naturally aged (NA) temper. The latter was made from a superlattice spot near the $\langle 100\rangle \mathrm{Al}$ zone axis SAD pattern shown in the insert. $\delta^{\prime} / \beta^{\prime}$ is the only matrix precipitate present in this temper. (c) A dark field image showing the typical dislocation structure in this temper. The dislocations in this temper are wavy and homogenously distributed. (d) Bright field and (e) dark field images, showing the precipitates in the overaged (OA) temper. Several precipitates including $T_{2}, T_{B}$ and $\delta^{\prime} / \beta^{\prime}$ are present in the matrix of this temper (f) Typical dislocation structure found in the OA temper. The dislocations are mostly planar and only present in specific planes.

\subsection{HEXRD}

The full ranges of the recorded HEXRD spectra for the two tempers of interest, NA and OA, are shown in Figure 3(a). Simulated $2 \theta$ positions of the different phases present in these tempers are included in the figure. The prominent peaks at $2 \theta \approx 3.04,3.51,4.96,5.82$, and 6.08 degrees for the two tempers were indexed as the Al phase. All the $2 \theta$ positions of the Al phase in the NA temper are however shifted to slightly larger $2 \theta$ values in comparison to those in the $\mathrm{OA}$ and simulated $\mathrm{Al}$ pattern. Enlarged portions of two of the $\mathrm{Al}$ peak positions for the NA and OA tempers are shown in Figure 3(b) to more clearly highlight the observed 
shift. The corresponding peak positions for the peak aged (PA) temper and that of the simulated $\mathrm{Al}$ phase are also included in the plot in order to establish a reference position.

The Al phase of the simulated diffraction pattern and that of the OA and PA tempers all have a lattice parameter of $4.05 \AA$, while that of the NA is $4.04 \AA$. The uniform shifts in $2 \theta$ peak positions of the NA temper, and the corresponding decrease in lattice parameter, relative to those of the $\mathrm{OA}$ and PA, are likely associated with the higher $\mathrm{Li}$ and $\mathrm{Cu}$ solute content in the NA temper. The APT analysis (see section 3.3) shows that the matrix solute content of Li and $\mathrm{Cu}$ is higher in the NA temper, while the $\mathrm{Mg}$ content is the same in both NA and OA tempers. It has been shown that the lattice parameter of $\mathrm{Al}$ decreases with increasing $\mathrm{Li}, \mathrm{Cu}$, Si and Zn content, while it increases with increasing Mg content [27]. Macroscopic residual stresses arising from the $2 \%$ pre-stretch given to the NA temper prior to aging may additionally contribute to the observed decrease in lattice parameter [28]. The decrease in matrix solute concentration due to precipitation of new phases in addition to the relief of residual stresses during aging at high temperature will lead to an increase in the lattice parameter of the artificially aged tempers, i.e. the OA and PA.

An enlarged region of the HEXRD spectra showing the main phases present in the NA and OA tempers is shown in Figure 3(c). Although five of the peaks associated with $\delta^{\prime}$ coincide with the $\mathrm{Al}$ peak positions, it can be argued that the $\delta^{\prime}$ precipitate is present in both tempers since there is a peak at $2 \theta \approx 5.58$, albeit weak, that coincides with one of the simulated $\delta^{\prime}$ peaks. In contrast, only two of the peaks in the experimental spectra coincide with the simulated $\beta^{\prime}$ peaks. However, it is not clear if $\beta^{\prime}$ is present in these tempers since these two peaks also coincide with the $\mathrm{Al}$ peak positions. Experimentally observed peaks associated with $\mathrm{T}_{\mathrm{B}}, \mathrm{T}_{2}$ and $\theta$ phases are also highlighted in Figure 3(c). The peaks at $2 \theta \approx 5.31$ and 5.45 can be assigned to both $T_{B}$ and $T_{2}$ precipitates. Close examination of the complete HEXRD spectra in Figure 3(a) however shows that while $T_{2}$ is present in both tempers, $T_{B}$ is present 
only in the OA temper. Since the relative intensities of all peaks that are exclusive to the $\mathrm{T}_{2}$ phase are similar in both tempers, it can be argued that its volume fraction is relatively constant; the $T_{2}$ phase must have thus existed prior to aging. Two such peaks can be found at $2 \theta \approx 1.83$ and 1.93 . This also implies that there was negligible dissolution or formation of the $\mathrm{T}_{2}$ phase during the heat treatment protocol employed in this investigation. On the other hand, the high intensities of the peaks associated with the $\mathrm{T}_{\mathrm{B}}$ precipitate at $2 \theta \approx 2.11,3.44$ and 4.04 corroborate the earlier proposition that the $\mathrm{T}_{\mathrm{B}}$ phase is the main phase that formed in the OA temper. The weak peaks at $2 \theta=2.56$ and 2.73 in both tempers could not be indexed with the simulated patterns of the known phases used in this study. 


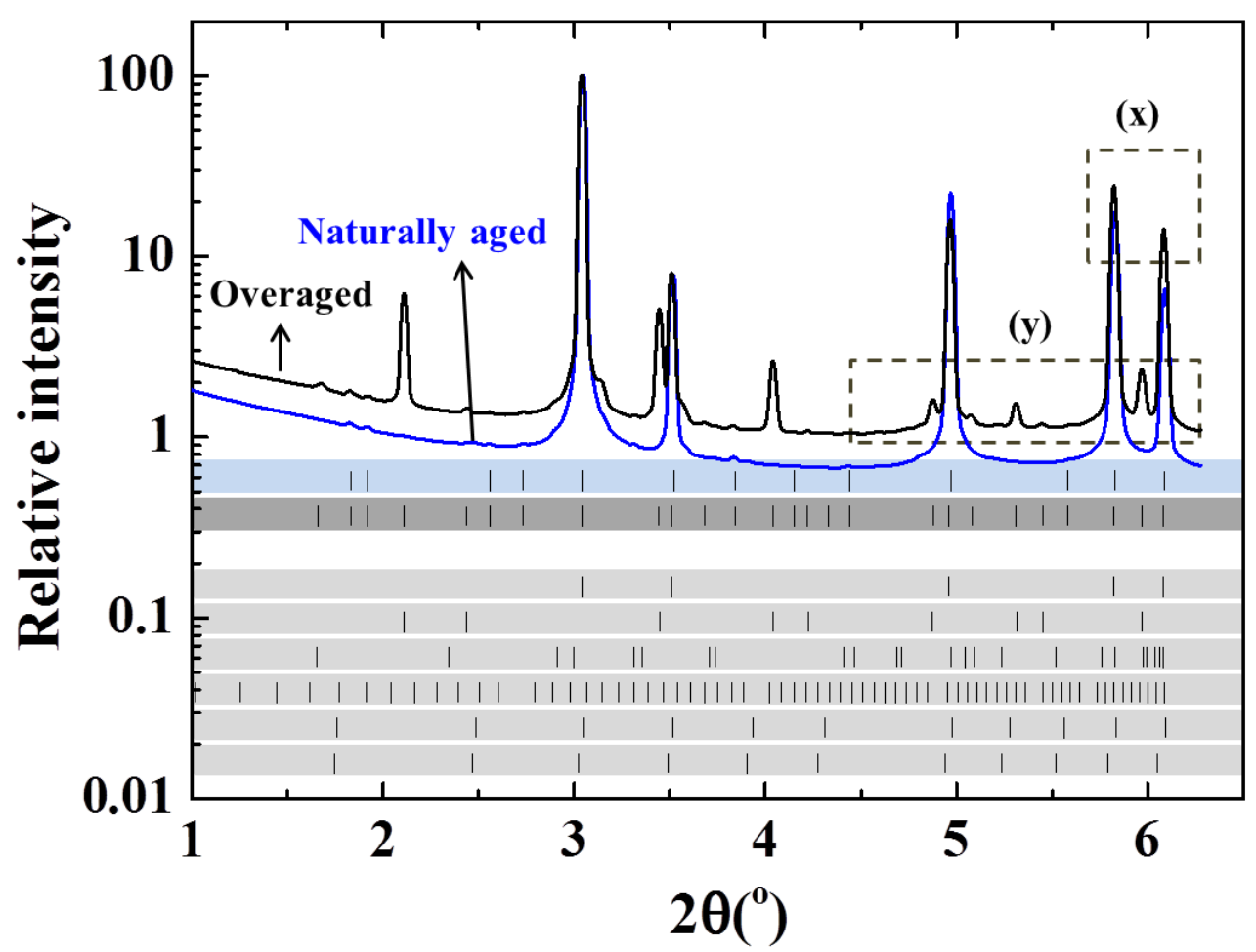

Experimental

Naturally aged Overaged

Simulated

Al

$\mathbf{T}_{\mathrm{B}}-\mathbf{A l}_{7} \mathrm{Cu}_{4} \mathbf{L i}$

$\boldsymbol{\theta}-\mathbf{A l}_{\mathbf{2}} \mathbf{C u}$

$\mathrm{T}_{2}-\mathrm{Al}_{5} \mathrm{CuLi}_{3}$

$\delta^{\prime}-\mathbf{A l}_{3} \mathbf{L i}$

$\boldsymbol{\beta}^{\prime}-\mathbf{A l}_{3} \mathbf{Z r}$

(a)

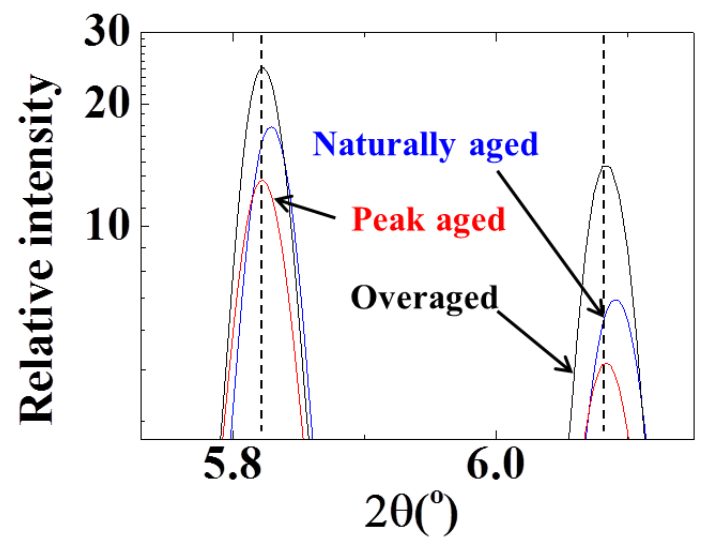

(b)

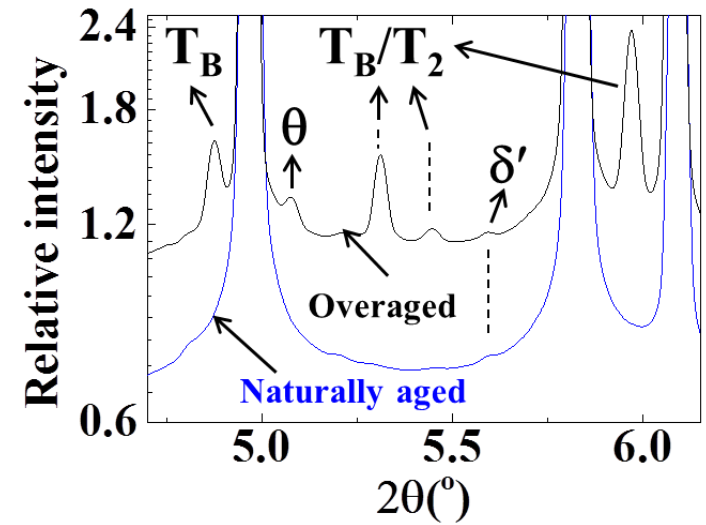

(c)

Figure 3: (a) The full experimental HEXRD spectra of the naturally aged (NA) temper in blue and overaged (OA) in temper in black, including the $2 \theta$ positions of the experimental and simulated phases. (b) A magnified plot of the area marked $\mathrm{x}$ in (a). Two prominent experimental Al peaks showing the shift of the Al peak associated with the naturally aged in comparison with OA, peak aged (in red) and the simulated Al phase (broken line). (c) A magnified plot of the section marked $\mathrm{y}$ in (a). Peaks associated with the $\mathrm{T}_{\mathrm{B}}, \mathrm{T}_{2}, \theta$ and $\delta^{\prime}$ phases can be easily identified in the plot. 


\subsection{Atom probe tomography (APT)}

Figure 4 shows $10 \mathrm{~nm}$ thick slices through reconstructed APT dataset measured from the NA and OA tempers. Data obtained for the main solute elements, $\mathrm{Li}, \mathrm{Cu}$ and $\mathrm{Mg}$ are shown separately. Except for a $\mathrm{Cu}$-rich precipitate at the very top of the NA specimen, no other precipitates were captured in the examined tips. The inability to capture the main precipitate phase, i.e. $\delta^{\prime} / \beta^{\prime}$ phase, which was observed in both the TEM and HEXRD investigation can be attributed to the relatively low volume fraction and the large inter-particle spacing $(\approx 78 \mathrm{~nm})$ of this phase in the investigated tempers, relative to the typical size of an APT dataset. A proxigram created using the interface of the $\mathrm{Cu}$-rich phase (not shown) at the top of the NA specimen indicate that it is most likely an equilibrium $\theta$ precipitate. This precipitate, like the $T_{2}$, must have been undissolved in the solution treating step. The elemental distribution of atoms in both tempers seems to be homogenous and there is no visible evidence of clustering of any of the elements. A good indication of solute clustering is nevertheless obtained by the use of cluster identification algorithms [29]. In preparation for cluster analysis, regions not belonging to the matrix phase were removed from the datasets. This included the $\mathrm{Cu}$-rich precipitate from the NA temper sample and a crystallographic pole (an APT measurement artefact) to which $\mathrm{Cu}$ atoms segregated slightly from the OA temper sample. In this work, the core-linkage (CL) algorithm technique was employed. The CL technique is a variation of the Density Based Clustering technique, in which clusters are defined as areas having a density higher than the reminder of the matrix. More details about the method can be found in literature [29]. The $d_{\text {core }}$ and $d_{\text {link }}$ parameters which define the CL algorithm were determined using an approach recently employed by Marceau [25]. Specifically, $d_{\text {core }}$ was set to the distance at which the difference between cumulative $5^{\text {th }}$ nearest neighbour distances $(5 \mathrm{NN})$ and its randomized counterpart was the highest $\left(d_{\text {core }}\right.$ $=1.58 \mathrm{~nm}$ and $2.35 \mathrm{~nm}$ for $\mathrm{Cu}-\mathrm{Cu}$ atoms in the NA and OA tempers respectively), while $d_{\text {link }}$ 
was set to $1 / 2 d_{\text {core. }}$ Only clusters consisting of at least 3 atoms were considered. The random data was generated from the experimental data; only the chemical identities of the atoms were randomized, their spatial positions were unchanged. 5NN frequency histograms of the main alloying elements, namely, $\mathrm{Li}-\mathrm{Li}, \mathrm{Cu}-\mathrm{Cu}, \mathrm{Mg}-\mathrm{Mg}$ and $\mathrm{Cu}-\mathrm{Mg}$ in the NA and $\mathrm{OA}$ tempers and their respective randomized distributions are presented in Figure 5. Evidence of clustering, indicated by the broadening and shifting of the distribution maxima of the experimental 5NN histogram, relative to the randomized 5NN histogram, to smaller distances [29][30], can mainly be seen between the $\mathrm{Cu}-\mathrm{Cu}$ atoms in the NA and OA tempers. A slight shift of the distribution maxima can also be observed between the experimental and random 5NN histograms of the Li-Li atoms in both tempers. Further analyses with the CL technique, which is a more accurate and efficient cluster identification technique [29], however show that significant clustering, exceeding what can be found in a randomized dataset, only occurred between the $\mathrm{Cu}-\mathrm{Cu}$ atoms in the NA temper. The size distribution of the $\mathrm{Cu}-\mathrm{Cu}$ clusters determined by the CL technique is plotted as a function of cluster size in Figure 6 for both the $\mathrm{NA}$ and the $\mathrm{OA}$ tempers. There is a significant difference between the $\mathrm{Cu}-\mathrm{Cu}$ cluster size distributions for the experimental and the randomized datasets of the NA temper but there is practically no difference between these distributions in the OA temper. Additionally, there is a significantly higher density of detected $\mathrm{Cu}-\mathrm{Cu}$ clusters in the NA temper $\left(1.25 \times 10^{25} \mathrm{~m}^{-3}\right)$ in comparison to the OA temper $\left(1.69 \times 10^{24} \mathrm{~m}^{-3}\right)$. Together these results are a strong indication that the contribution of the clusters to strength will be much higher in the NA temper than in the OA temper." On the other hand, there is practically no difference between the number of CL-detected Li-Li clusters in the experimental and in the randomized datasets in both tempers. This indicates that Li-Li clusters do no form in the NA and OA tempers of AA2198. 
The overall matrix concentration of the main alloying elements of the NA and OA tempers obtained from the APT measurements is given in Table 1. Over six million atoms were captured in each test. Atoms of $\mathrm{Zr}$ were not detected in the measurements, probably because of its very low concentration in the alloy and because most of the $\mathrm{Zr}$ atoms might be located in $\mathrm{Al}_{3} \mathrm{Zr}$ precipitates. Additionally, the location of the $\mathrm{Zr}^{2+}$ peaks in the "thermal tail" of the main $\mathrm{Al}^{+}$peak leads to a higher noise level in the mass-to-charge spectrum and hence complicates the accurate detection of the $\mathrm{Zr}$ atoms. Si was overestimated in both samples. The probable cause of this, the overlap between $\mathrm{Si}$ and $\mathrm{AlH}_{\mathrm{n}}$ peaks has been explained earlier. Regardless, the experimental concentrations of the main alloying elements are comparable with the nominal concentration and can therefore be taken as good indication of the global matrix concentration of this alloy after ageing. A significant decrease in the matrix $\mathrm{Cu}$ concentration of the $\mathrm{OA}$ temper relative to that of the NA temper was recorded. This large decrease, of about $64 \%$, is associated with the formation of the high volume fraction of large equilibrium $\mathrm{Cu}$-rich precipitates, such as $\mathrm{T}_{\mathrm{B}}$, in the overaged state. The high peak intensity of the $T_{B}$ precipitate as seen in the HEXRD spectra is a clear indication that its volume fraction is high in the OA temper. The matrix Li concentration in the OA temper was only slightly less than that of the NA temper. It can be argued that although the TEM and HEXRD analysis show that the $T_{B}$ phase is present in significant amounts, its presence is not expected to lead to a significant depletion of $\mathrm{Li}$ from the matrix considering that the percentage composition of $\mathrm{Li}$ in $\mathrm{T}_{\mathrm{B}}$ is only $1.54 \%$. The $\mathrm{Mg}$ concentration however remained unchanged. 
Table 1: Overall matrix concentration of the naturally aged (NA) and overaged (OA) tempers as measured from APT experiments. The concentration range given by the manufacturer is also included in the table.

\begin{tabular}{ccccccc}
\hline Element at.\% & $\mathbf{L i}$ & $\mathbf{C u}$ & $\mathbf{M g}$ & $\mathbf{A g}$ & $\mathbf{Z r}$ & $\mathbf{S i}$ \\
\hline Nominal & $3.11-4.27$ & $1.23-1.48$ & $0.29-0.80$ & $0.03-0.12$ & $0.01-0.05$ & 0.08 \\
NA & 3.24 & 1.10 & 0.26 & 0.15 & - & 0.28 \\
OA & 3.14 & 0.40 & 0.26 & 0.04 & - & 0.18 \\
\hline
\end{tabular}
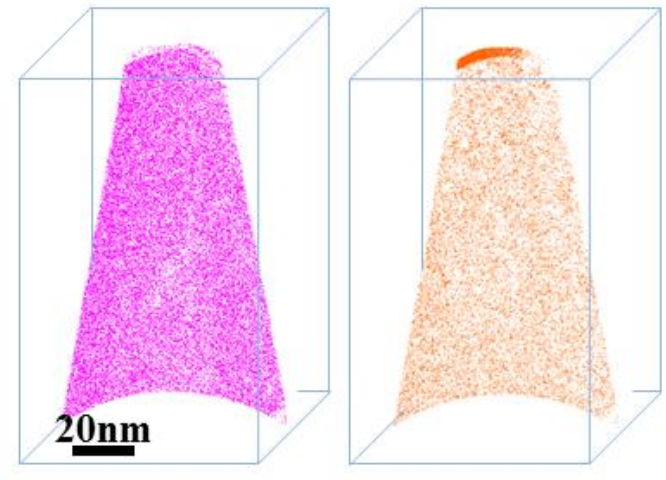

(a)
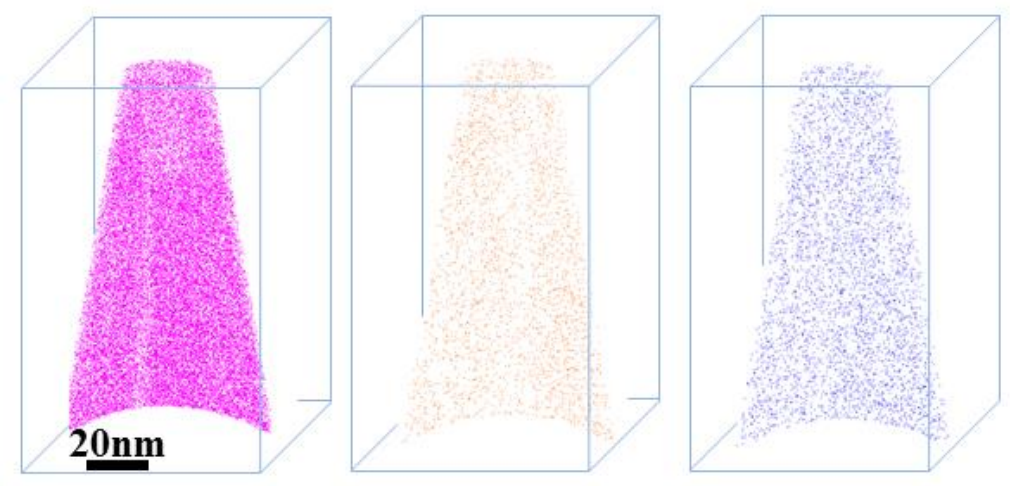

(b)

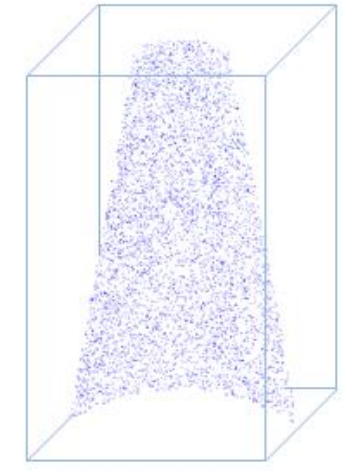

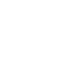
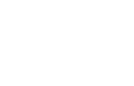

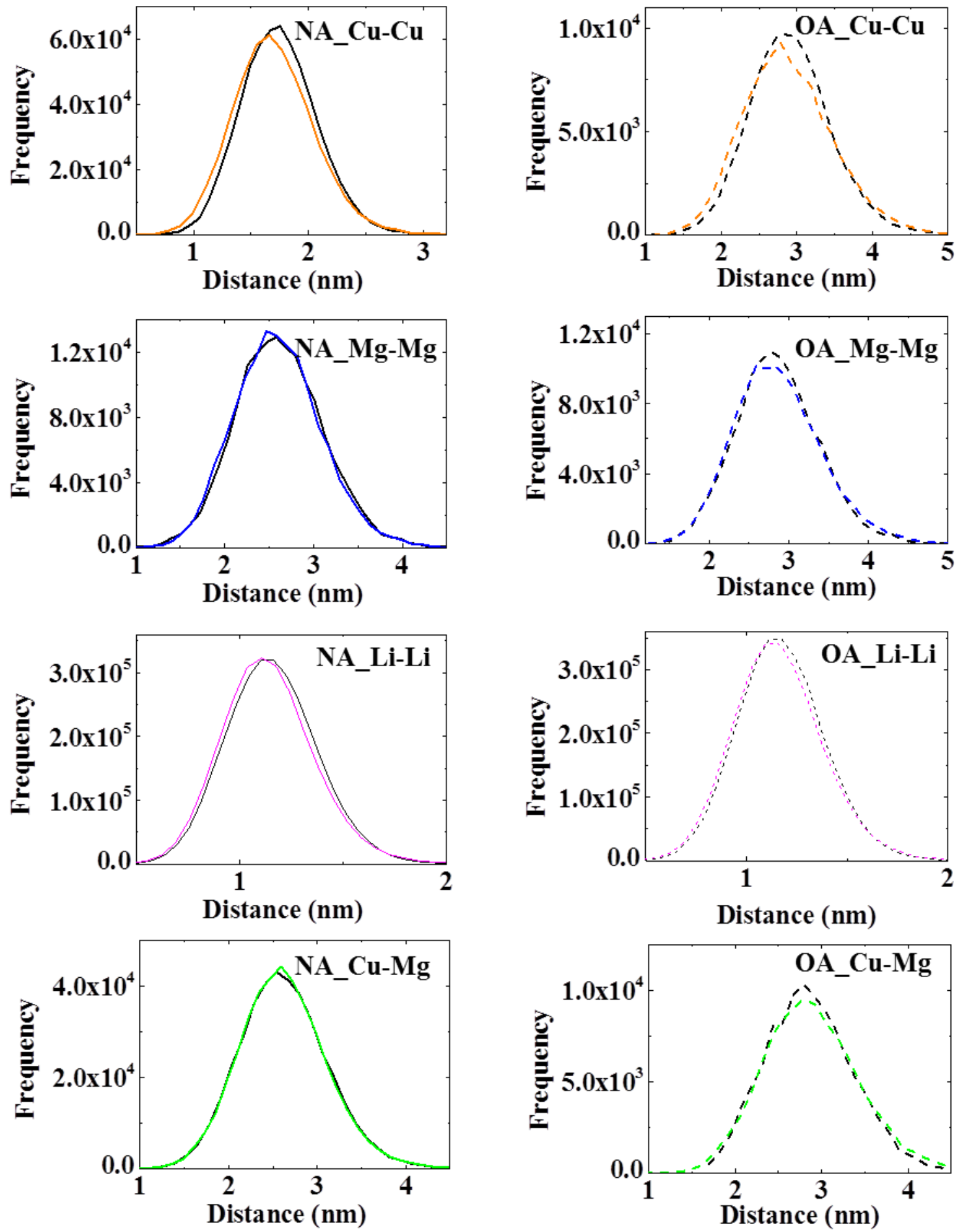

Figure 5: Frequency histograms of $5^{\text {th }}$ nearest neighbour distances $(5 \mathrm{NN})$ between atoms of the naturally aged (NA) temper, in straight lines and the overaged (OA) temper, in broken lines. The distribution of the main atomic species, $\mathrm{Li}-\mathrm{Li}$ (pink), $\mathrm{Cu}-\mathrm{Cu}$ (orange), $\mathrm{Mg}-\mathrm{Mg}$ (blue), $\mathrm{Cu}-\mathrm{Mg}$ (green) and their respective randomised distribution (black) are also presented. 


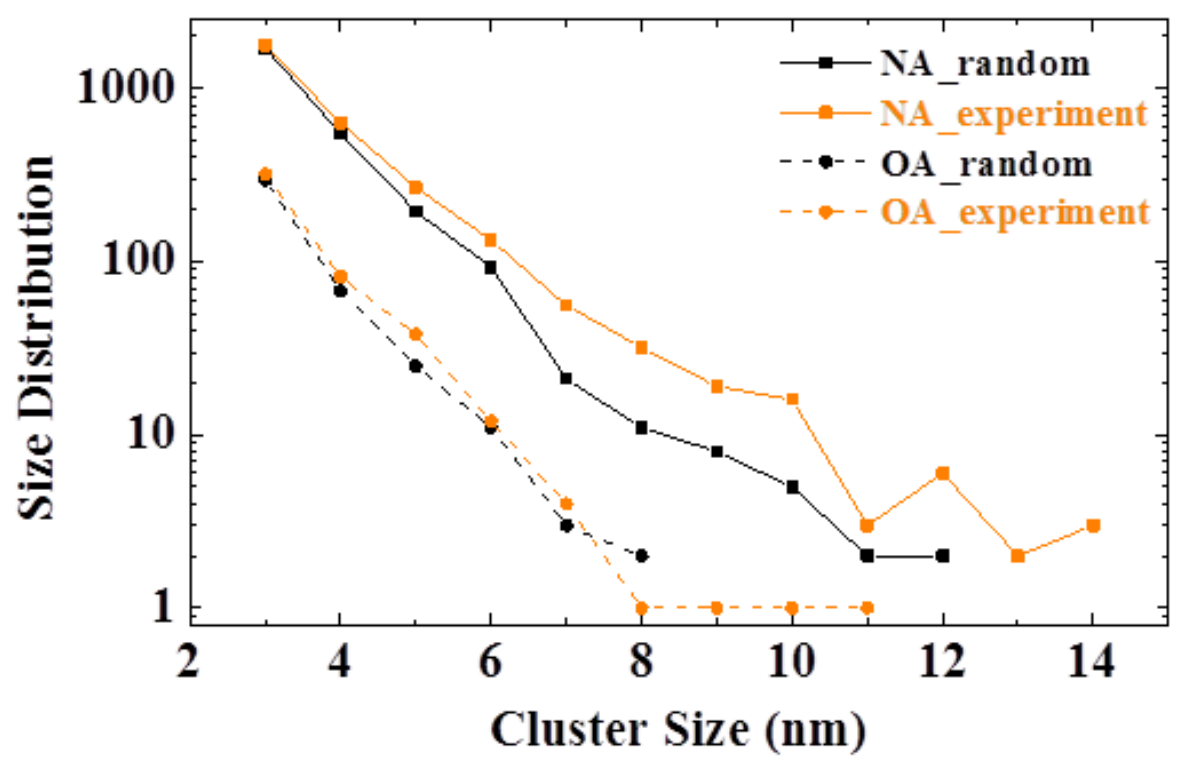

Figure 6: The size distribution of the $\mathrm{Cu}-\mathrm{Cu}$ clusters in the naturally aged, NA, (straight orange line) and overaged, OA, (broken orange line) tempers. The respective randomized distribution for the NA (straight black line) and OA (broken black line) tempers is also included in the plot.

\section{Discussion}

The preceding microstructural analyses indicate that there are a number of obstacles to dislocation glide in the investigated tempers. The mechanical behaviour of each temper is nonetheless governed by the obstacle that provides the greatest resistance to dislocation glide. The obstacle governing strength in each temper, i.e. NA and OA, is now investigated by invoking known relations for estimating the theoretical strength provided by the obstacles observed in these tempers.

Major sources of strengthening in the NA temper include the $\delta^{\prime} / \beta^{\prime}$ precipitate revealed by both TEM and HEXRD, $\mathrm{Cu}-\mathrm{Cu}$ solute clusters revealed by the APT measurements and matrix solute atoms. It is well established that strengthening by the $\delta^{\prime}$ phase, which is a longrange ordered phase, is due to order hardening; a mechanism that leads to the creation of an antiphase boundary (APB) on the slip plane of an ordered coherent precipitate upon shearing by matrix dislocations [31][33]. The energy of the APB represents the resistance that must be 
overcome by the matrix dislocations for slip to occur. The theoretical critical resolved shear stress (CRSS) predicted by order hardening $\tau^{O H}$, can be estimated from [36]:

$$
\tau^{O H}=\frac{\gamma_{a p b} f^{\frac{1}{2}}}{2 b}\left[1.731\left(\frac{\pi \gamma_{a p b} r_{o}}{4 G b^{2}}\right)^{\frac{1}{2}}-f^{\frac{1}{2}}\right],
$$

where $\gamma_{a p b}$ is the antiphase boundary energy, $G$ is the shear modulus, $b$ is the Burgers vector, $r_{o}$ is the average precipitate radius and $f$ the volume fraction of the precipitates. Since it was not possible in this work to clearly distinguish between the $\delta^{\prime} / \beta^{\prime}$ precipitates, the CRSS, $\tau^{\mathrm{OH}}$, was estimated with the well-known order hardening parameters for $\delta^{\prime}$. This approach is considered to be reasonable even in the case of $\delta^{\prime} / \beta^{\prime}$ core-shell precipitates since the coreshell interface has been shown to be coherent, with the atomic planes bending only slightly across the interface [34]. Using the Taylor factor of 2.95 [18], $G=30 \mathrm{GNm}^{-2}$ [32], $b=$ $0.2864 \mathrm{~nm}[32], \gamma_{a p b}=0.15 \mathrm{Jm}^{-2}[32]$, and the experimentally determined values of $r_{o}=10 \mathrm{~nm}$ and $f=0.004$, the theoretical yield strength due to order hardening, $\sigma_{y}^{O H}$, is found to be $55 \mathrm{MPa}$ for the NA temper. The experimentally found yield strength for this temper is $310 \mathrm{MPa}$. It follows that order hardening is not the governing strengthening mechanism in this temper.

The contribution to strength from the unclustered atoms of the main alloying elements, i.e., $\mathrm{Li}, \mathrm{Cu}$ and $\mathrm{Mg}$, in the matrix of the $\mathrm{NA}$ temper was determined from the classical relationships given in equations (2) and (3) [35]. These relationships predict the contribution to solution strengthening from the size misfit interaction, $\tau^{\mathrm{EI}}$, and the modulus misfit interaction, $\tau^{\mathrm{MI}}$. The CRSS due to solution strengthening, $\tau_{x}^{\mathrm{SS}}$, from a solute element, $\mathrm{x}$, is equal the sum of equations (2) and (3).

$$
\tau^{\mathrm{EI}}=1.26 G\left(0.1 \varepsilon_{\mathrm{a}}\right)^{4 / 3} c_{x}{ }^{2 / 3},
$$




$$
\tau^{\mathrm{MI}}=1.26 G\left[\frac{1}{32 \pi^{2}} \varepsilon_{\mathrm{G}}\left(1+\frac{\varepsilon_{\mathrm{G}}}{2}\right)^{-1}\right]^{4 / 3} c_{x}{ }^{2 / 3}
$$

The term $c_{x}$ in equations (2) and (3) is the concentration of the solute element, while $\varepsilon_{\mathrm{G}}$ and $\varepsilon_{\mathrm{a}}$ are the size misfit and modulus misfit parameters respectively. After Marceau [25], the total CRSS due to solution strengthening, $\tau^{\mathrm{SS}}$, is taken as:

$$
\tau^{\mathrm{SS}}=\sqrt{\tau_{L i}^{\mathrm{SS}}{ }^{2}+\tau_{C{ }^{\mathrm{SS}}}^{2}+\tau_{M g}^{\mathrm{SS}}}
$$

The effective matrix concentration of $\mathrm{Cu}$ in both NA and OA tempers decreased to 0.89 and 0.25 at.\%, respectively, after the $\mathrm{Cu}$ atoms tied up in the $\mathrm{Cu}-\mathrm{Cu}$ clusters were deducted from the global matrix $\mathrm{Cu}$ concentrations. $\mathrm{Mg}$ and $\mathrm{Li}$ did not form any cluster or co-cluster and so their matrix concentrations are effectively equal to the values in Table 1. Literature values of $\varepsilon_{\mathrm{G}}$ for $\mathrm{Li}, \mathrm{Cu}$ and $\mathrm{Mg}$ are $4,0.48$ and 0.87 , respectively, while the values for $\varepsilon_{\mathrm{a}}$ are $10^{-2},-0.35$ and 0.37 respectively [35]. Therefore the contribution to the yield strength of the NA temper due to $\mathrm{Li}, \mathrm{Cu}$ and $\mathrm{Mg}$ in solution, $\sigma_{y}^{S S}$, is predicted to be $63 \mathrm{MPa}$. Since this value is significantly less than the experimentally observed yield strength it can be argued that strengthening in this temper is largely governed by the $\mathrm{Cu}-\mathrm{Cu}$ clusters, which have been found through APT analysis to be present in large amounts. This is consistent with the conclusions made by Decreus [1] and Deschamps [12]. Nonetheless, the contributions of the other constituent obstacles, in particular the $\delta^{\prime} / \beta^{\prime}$ precipitates which were not observed in the Decreus work [1], along with the various solute atoms present in the matrix, cannot be ignored; they may contribute up to half of the total experimentally observed yield strength.

In the case of the OA temper, both TEM and HEXRD investigations reveal that several different precipitates, including $\mathrm{T}_{\mathrm{B}}, \mathrm{T}_{2}, \theta$ and $\delta^{\prime}$, are present in the OA temper. The APT cluster analysis also indicates that a small amount of $\mathrm{Cu}-\mathrm{Cu}$ clusters will be present. It can be argued that the $T_{B}$ precipitate has a significantly higher volume fraction than those of the 
other precipitate species since its HEXRD peak intensity is significantly higher than those of the other precipitate species. Although the presence of the $\delta^{\prime} / \beta^{\prime}$ phase in this temper is somewhat surprising, its continued presence can be partly attributed to its relative stability, which is a consequence of its coherency with the matrix [6]. This is supported by the work of Lee [37], which shows that the coarsening rate of $\delta^{\prime}$ in Al-Li binary alloys is significantly reduced by the addition of small amounts of Ag. Similarly, Radmilovic [38] argue that $\mathrm{L}_{2}$ core/shell precipitates, such as $\delta^{\prime} / \beta^{\prime}$, exhibit extremely low coarsening rates.

The main strengthening precipitate present in the OA temper is the $\delta^{\prime} / \beta^{\prime}$ phase. The contribution to yield strength from equilibrium phase precipitates such as $T_{B}, T_{2}$, and $\theta$ is known to be negligibly small [39]. According to equations (1) and (4), the theoretically predicted yield strength due to order hardening, $\sigma_{y}^{O H}$, in the OA temper is $71 \mathrm{MPa}$, while the theoretically predicted yield strength due to solute strengthening, $\sigma_{y}^{S S}$, is $38 \mathrm{MPa}$, respectively. Its experimental yield strength, $\sigma_{y}^{\text {exp }}$, is $133 \mathrm{MPa}$. Although additional contribution to strength is be expected from the $\mathrm{Cu}-\mathrm{Cu}$ clusters, grain boundaries and dislocations still present in the matrix, it can be argued that order hardening governs strength in the OA temper and not Orowan hardening as is the case for overaged tempers of most precipitation strengthened alloys. It can be further argued that the strengthening from the $\mathrm{Cu}$ $\mathrm{Cu}$ clusters in the OA temper in comparison to the NA temper will be very small because of the significantly lower number density of clusters in the former.

Although the significant difference in yield strength between the NA and OA was expected, the difference in their post yield behaviour, and specifically the absence of plastic instability in the NA temper and its presence in the OA temper, is remarkable. The occurrence of plastic instability in Al-Li based alloys have been largely attributed to dynamic strain aging of temporarily trapped mobile dislocations by Li atoms [40][42]. This cannot however explain the absence of plastic instability in the NA temper. The APT analysis show 
that the Li content of the OA temper which exhibited plastic instability is less than that of the NA temper. The result rather indicate that occurrence of plastic instability is associated with order hardening, which is the governing strengthening mechanism in the OA temper. A detailed investigation of the underlying mechanism for plastic instability in these alloy systems is presented elsewhere [16].

\section{Conclusion}

The effect of microstructural changes on the strengthening mechanism associated with the $\delta^{\prime}$ phase in a commercial Al-Cu-Li-Mg-Zr based alloy AA2198 was investigated using a combination of tensile test, APT, HEXRD and TEM methods. In contrast to previous reports [1], [12] that no precipitate is present in stretched and naturally aged (NA) AA2198, our results show the $\delta^{\prime} / \beta^{\prime}$ precipitate is present and remains in the matrix of the alloy even after extensive overaging. Based on quantitative analyses of the contribution of the $\delta^{\prime} / \beta^{\prime}$ precipitates and the solute atoms, it was shown that up to half of the strength in the NA temper is provided by obstacles other than solute clusters. This strongly indicates that the remarkably high strength in this temper is the result of the combination of several obstacles to dislocation glide, not just the $\mathrm{Cu}-\mathrm{Cu}$ solutes. On the other hand, several precipitates including $\mathrm{T}_{\mathrm{B}}, \mathrm{T}_{2}, \theta$ and $\delta^{\prime}$ phase were observed in the overaged (OA) temper. It was shown, albeit qualitatively, that the $T_{B}$ phase had a significantly higher volume fraction than the other phases. Based on theoretical considerations and experimentally determined parameters, it was determined that strength in the OA temper is governed by order hardening, which is the strengthening mechanism associated with $\delta^{\prime}$ precipitate. 


\section{Acknowlegdement}

Mr. Uwe Lorenz is grateful appreciated for technical support offered while carrying out the TEM experiments. Some of the TEM investigation was carried out at the National Centre for Electron Microscopy (NCEM) at Lawrence Berkeley Laboratory, which is supported by the U.S. Department of Energy under Contract \# DE-AC02-05CH11231.

\section{References}

[1] B. Decreus, A. Deschamps, F. De Geuser, P. Donnadieu, C, Sigli, M. Weyland. Acta Mater. 61 (2013) 2207-2218.

[2] E.J. Lavernia, N.J. G rant, J. Mater. Sci. 22 (1987) 1521-1529.

[3] R.J. Rioja, J. Liu, Met. Mater. Trans. A 43 (2012) 3325-3337.

[4] J.W. Martin, Ann. Rev. Mater. Sci. 18 (1988) 101-119.

[5] P. Donnadieu, Y. Shao, F. De Geuser , G.A. Botton, S. Lazar, M. Cheynet, M. De Boissieu, A. Deschamps, Acta Mater. 59 (2011) 462-472.

[6] S.C. Wang, M.J. Starink, Intl. Mater. Rev. 50 (2005) 193-215.

[7] Z. Chen, K. Zhao, L. Fan, Mater. Sci. Eng. A 588 (2013) 59-64.

[8] Y.S. Lee, J. Mater. Sci. Letters 17 (1998) 1161-1164.

[9] V. Araullo-Peters, B. Gault, F. De Geuser, A. Deschamps, J. Cairney, Acta Mater. 66 (2014) 199-208.

[10] T. Dorin, F. De Geuser, W. Lefebvre, C. Sigli, A. Deschamps, Mater. Sci. Eng. A 605 (2014) 119-126.

[11] T. Dorin, A. Deschamps, F. De Geuser, C. Sigli, Acta Mater. 75 (2014) 134-146.

[12] A. Deschamps, B. Decreus, F. De Geuser, T. Dorin, M. Weyland, Acta Mater. 61 (2013) 4010-4021. 
[13] M. Knüver, J. Schumacher, H. Ribes, F. Eberl, B. Bes, 17th AeroMat Conf \& Expo., May 15-18, 2006, Seattle-Washington.

[14] N.D. Alexopoulos, E. Migklis, A. Stylianos, D.P. Myriounis. Intl. J. Fatigue 56 (2013) 95-105.

[15] J. Rao, E.J. Payton, C. Somsen, K. Neuking, G. Eggeler, A. Kostka, J.F. Dos Santos, Adv. Eng. Mater. 12 (2010) 298-303.

[16] H. Ovri, E.T. Lilleodden. Acta Materialia 89 (2015) 88-97.

[17] R.C. Picu, G. Vincze, F. Ozturk, J.J. Gracio, F. Barlat, A.M. Maniatty, Mater. Sci. Eng. A 390 (2005) 334-343.

[18] M.J. Starink, P. Wang, I. Sinclair, P.J. Gregson, Acta Mater. 47 (1999) 3855-3868.

[19] M.J. Starink, P. Wang, Acta Mater. 57 (2009) 2376-2389.

[20] W. Lefebvre, K. Hoummada, B. Decreus, F. de Geuser, In: J. Hirsch, B. Skrotzki, G. Gottstein (Eds.), Proceedings of the 11th Intl Conf on Al alloys, Aachen, Germany, vol. 1, Wiley-VCH Weinheim, 2008. pp. 801-807.

[21] P.S. Chen, B.N. Bhat, NASA/TM 211548, 2002.

[22] N. Schell, A. King, F. Beckmann, T. Fischer, M. Müller, A. Schreyer. Mater. Sci. Forum 772 (2014) 57-61.

[23] B. Gault. F. de Geuser, L. Bourgeois, B.M. Gabble, S.P. Ringer, B.C. Muddle. Ultramicr. $111(2011) 683-689$.

[24] M.K. Miller, K.F. Russell, G.B. G.B. Thompson. Ultramicroscopy 102 (2005) 287298.

[25] R.K.W. Marceau, A. De Vaucorbeil, G. Sha, S.P. Ringer, W.J. Poole, Acta Mater 61 (2013) 7285-7303. 
[26] M.F. Ashby, Phil. Mag. 14 (1966)1157-1178.

[27] H.J. Axon, W. Hume-Rothery. Proc. Roy. Soc. London A, 193:1032 (1948) 1-24.

[28] W. Reimers, A.R. Pyzalla, A. Schreyer, H. Clemens (Eds.), Neutrons and synchrotron radiation in engineering materials science, Wiley-VCH, Weinheim, 2008.

[29] B. Gault, M.P. Moddy, J.M. Cairney, S.P. Ringer, Atom probe microscopy, Springer, 2012, New York.

[30] R.K.W. Marceau, G. Sha, R. Ferragut, A. Dupasquier, S.P. Ringer, Acta Mater 58 (2010) $4923-4939$.

[31] A.J. Ardell, Metall. Trans. A 16 (1985) 2131.

[32] J.C. Huang, A.J. Ardell. Mater Sci Eng A 104 (1988)149-156.

[33] C. Schlesier, E. Nembach, Acta Metall. Mater. 43 (1995) 3983-3990.

[34] N. Kim, J. Howe, E. Boden. J. de Phys. Collo. 48 (1987) C3-457 - C3-463.

[35] P. Gomiero, Y. Brechet, F. Louchet, A. Tourabi, B. Wack, Acta Metall. et. Mater. 40 (1992) 857-861.

[36] A.S. Argon, Strengthening mechanisms in crystal plasticity, Oxford Uni. press, Oxford, 2008.

[37] B.C. Lee, J.K. Park, Acta Mater. 46 (1998) 4181-4187.

[38] V. Radmilovic, A. Tolley, E.A. Marquis, M.D. Rossell, Z. Lee, U. Dahmen, Scr. Mater. 58 (2008) 529-532.

[39] H.R. Shercliff, M.F. Ashby, Acta Metall. Mater. 38 (1990) 1789-1802.

[40] S. Kumar, J. Król, E. Pink, Scr. Mater. 35 (1996) 775-780.

[41] P.J. Gregson, D.S. McDarmaid, E. Hunt, Mater. Sci. Tech. 4 (1988) 713-718.

[42] M. Cieslar, P. Vostrý, I. Stulíková. Phys. Stat. Sol. 157 (1996) 217-227. 


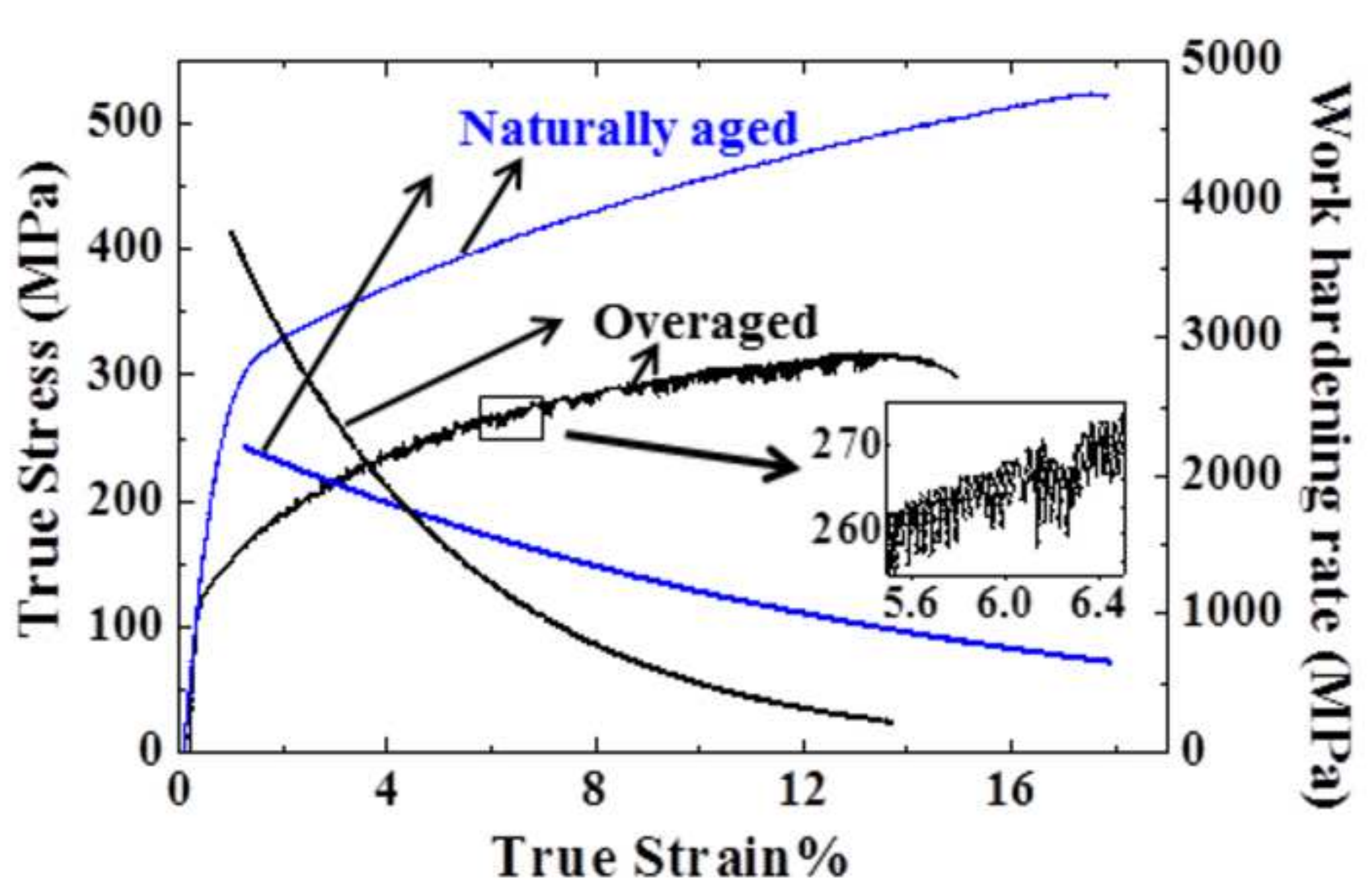


Figure 2
Click here to download high resolution image
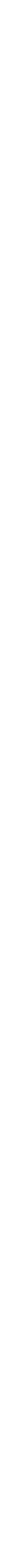

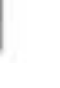




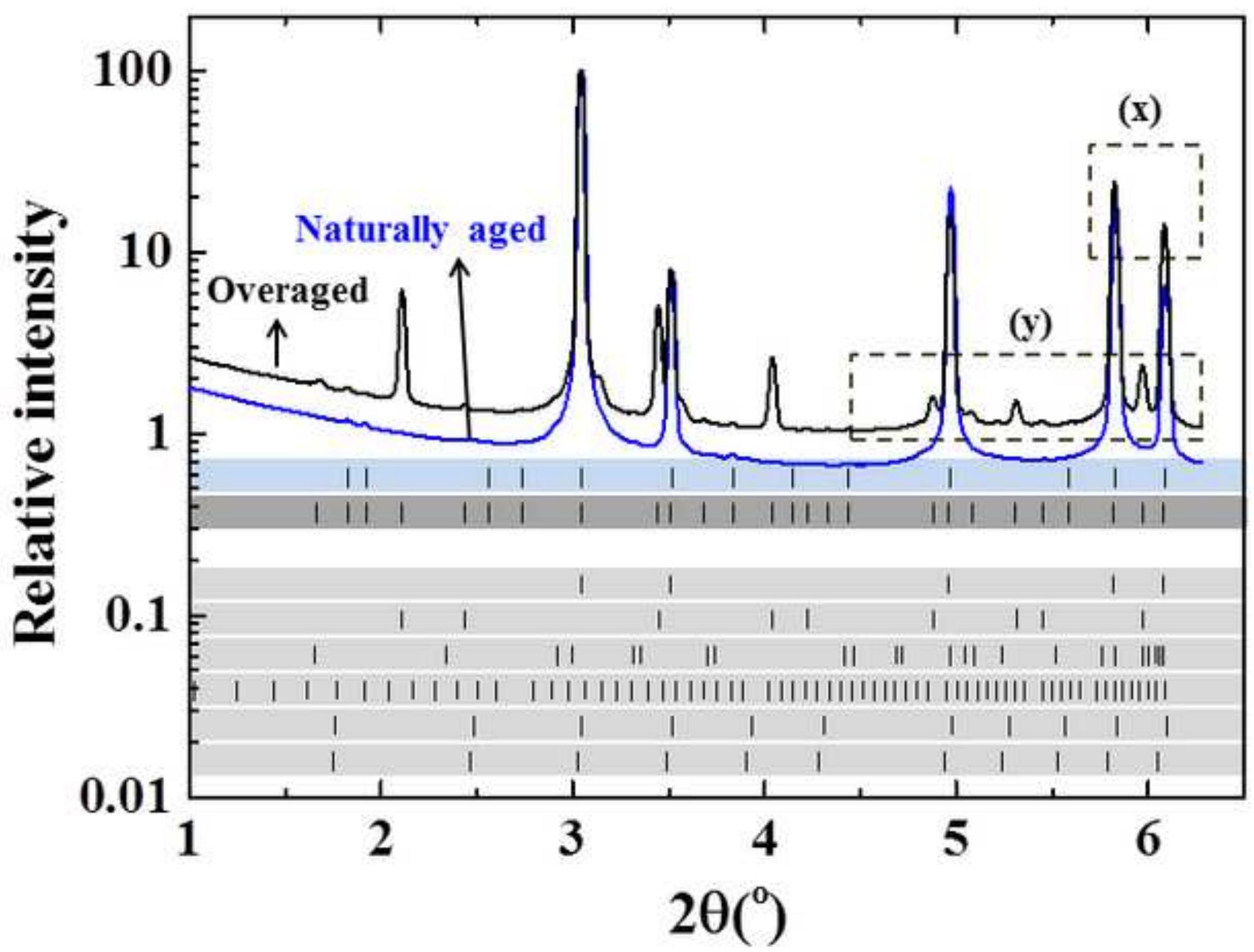

Experimental

Naturally aged Overaged

Simulated

Al

$\mathrm{T}_{\mathrm{B}}-\mathrm{Al}_{7} \mathrm{Cu}_{4} \mathrm{Li}$

$\boldsymbol{\theta}-\mathrm{Al}_{2} \mathrm{Cu}$

$\mathrm{T}_{2}-\mathrm{Al}_{5} \mathrm{CuLi}_{3}$

$\delta^{\prime}-\mathrm{Al}_{3} \mathrm{Li}$

$\beta^{\prime}-\mathrm{Al}_{3} \mathrm{Zr}$

$2 \theta\left({ }^{\circ}\right)$ 

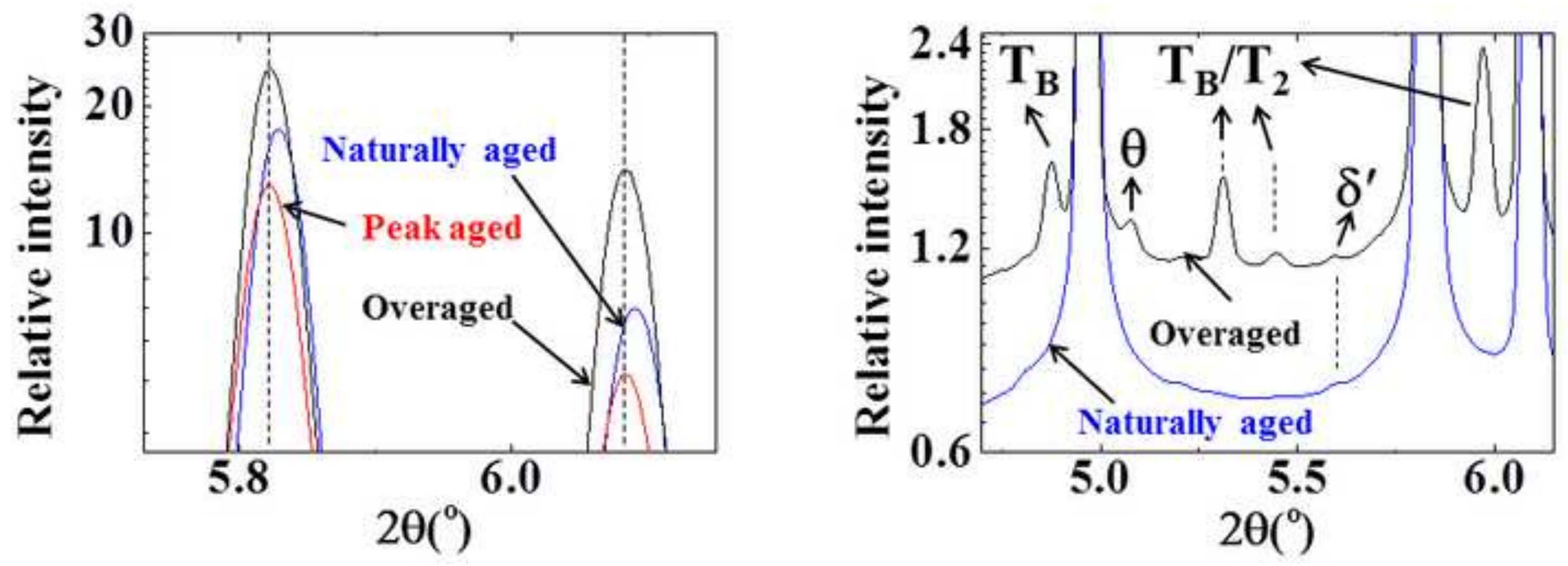

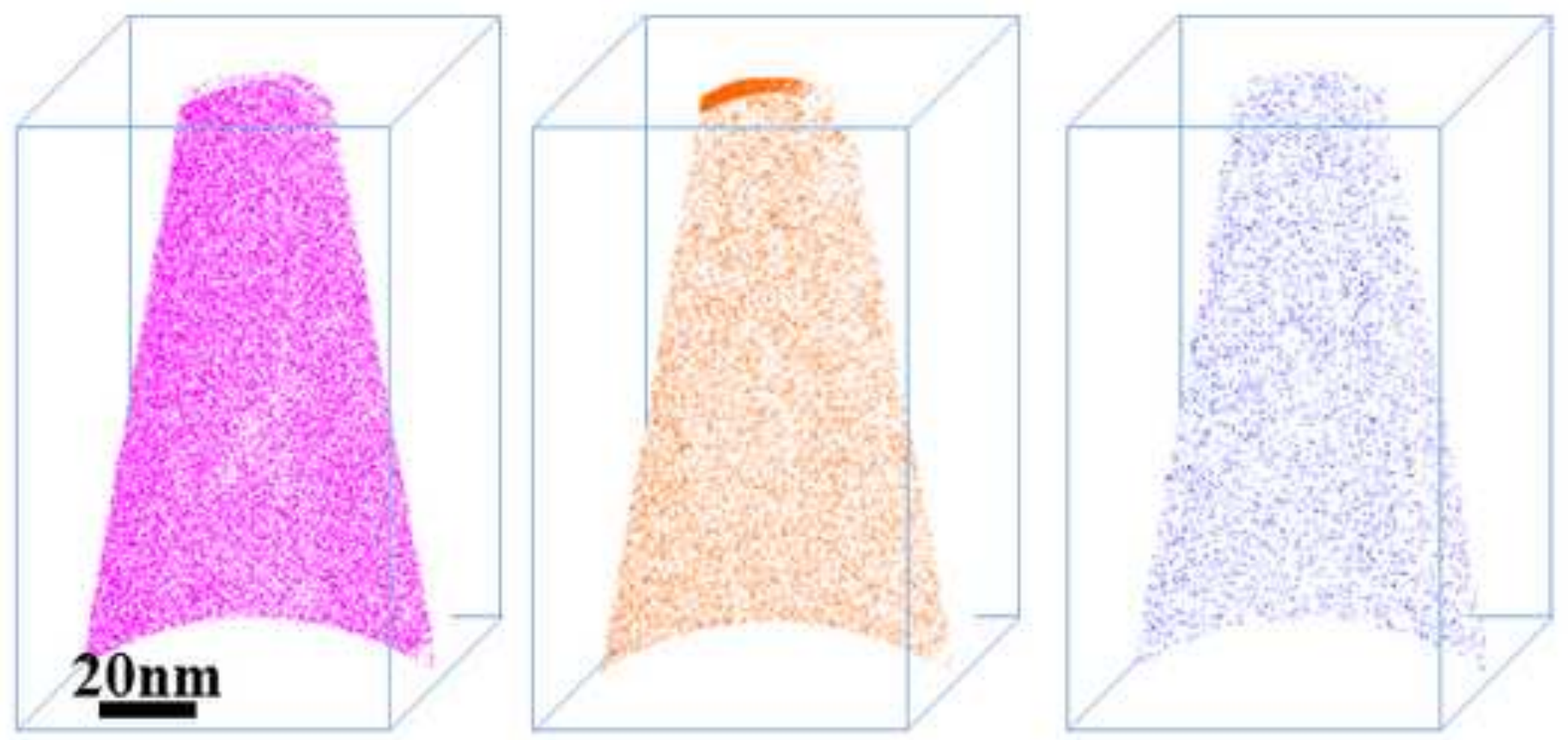

(a)
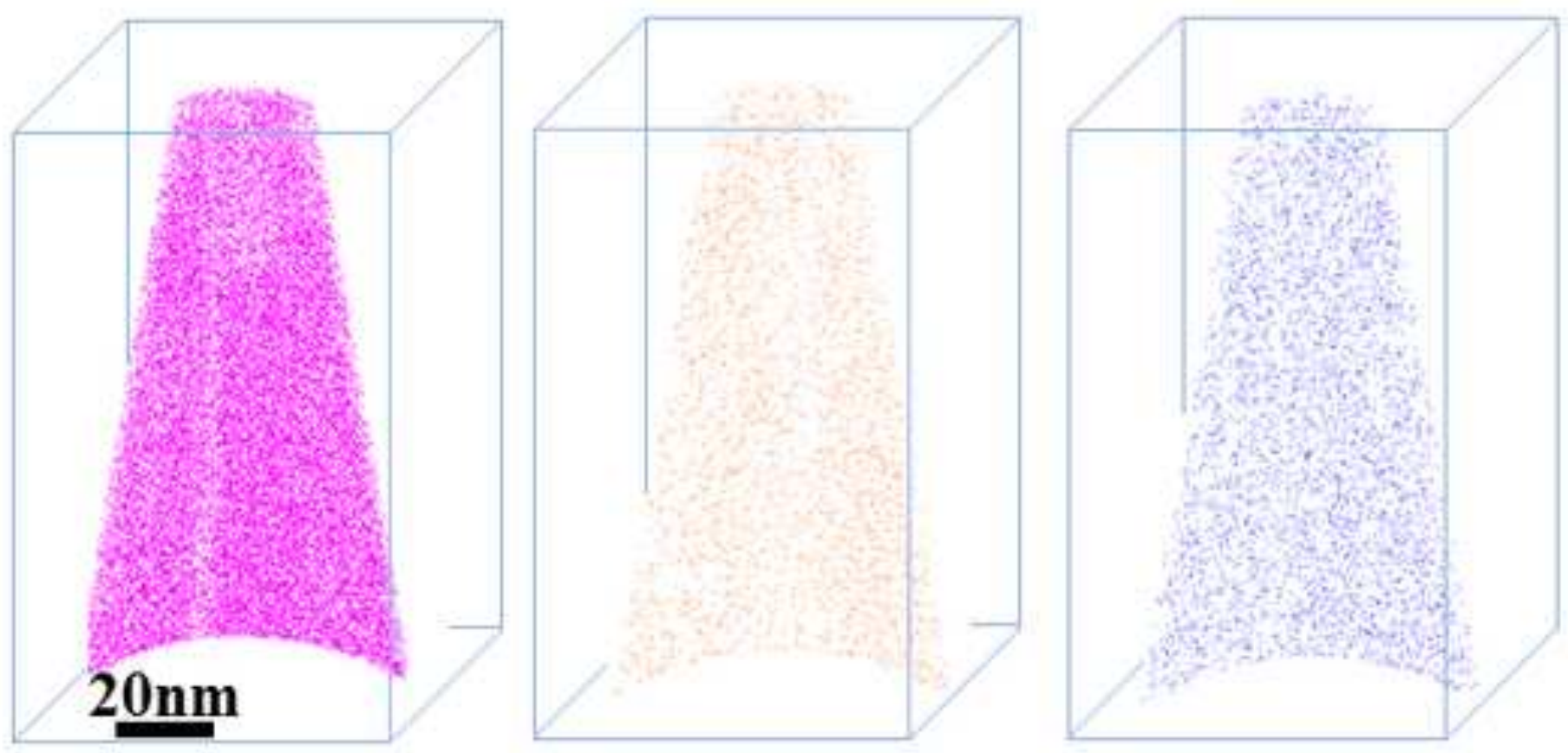

(b) 

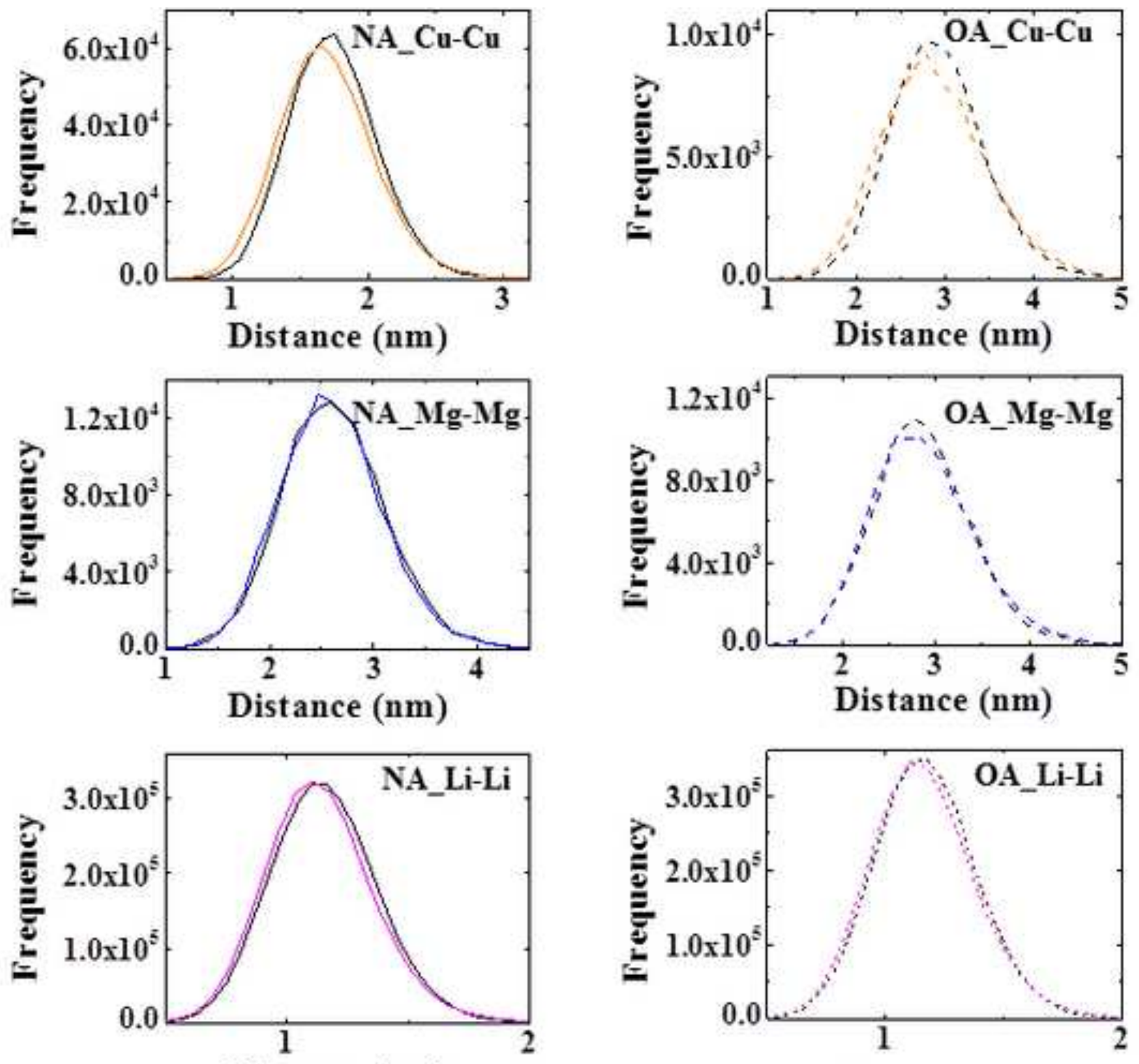

Distance (nm)
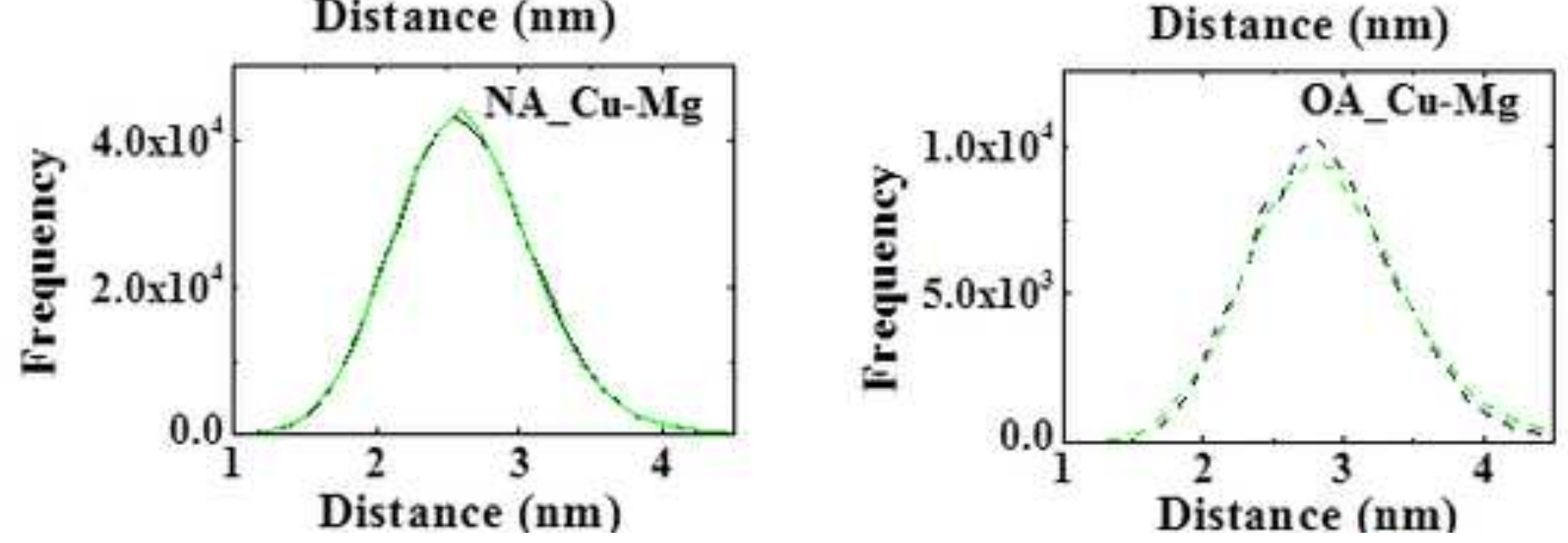


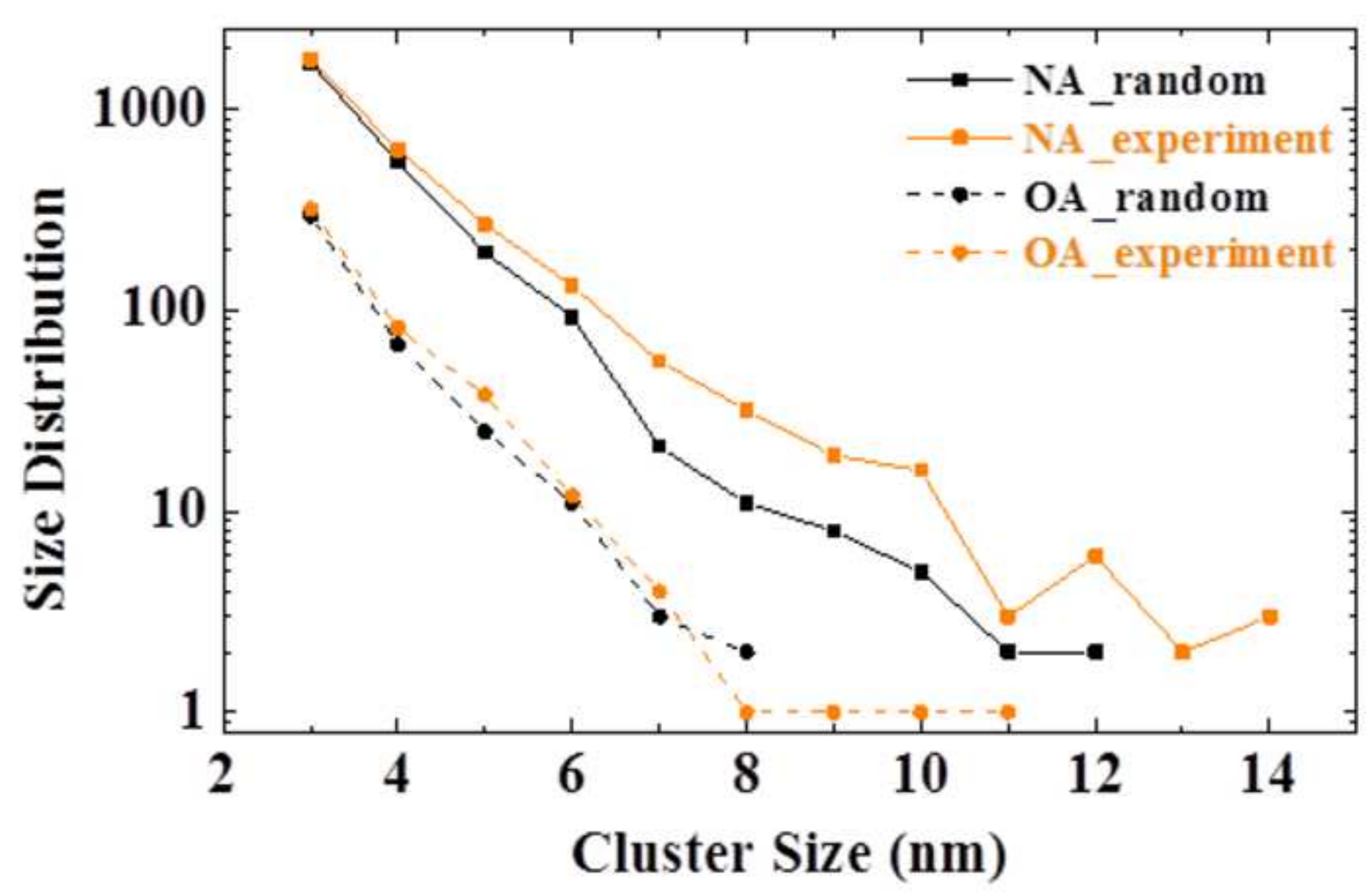

